CLINICAL STUDY

\title{
Health-related quality of life and IGF-1 in GH-deficient adult patients on GH replacement therapy: analysis of the German KIMS data and the Study of Health in Pomerania
}

\author{
Joern Moock, Christin Albrecht ${ }^{1}$, Nele Friedrich, Henry Völzke, Matthias Nauck ${ }^{2}$, Maria Koltowska-Haggström ${ }^{3,4}$, \\ Thomas Kohlmann* and Henri Wallaschofski ${ }^{1, *}$ \\ Institut for Community Medicine, Ernst Moritz Arndt University of Greifswald, Walther-Rathenau-Straße 48, D-17475 Greifswald, Germany, \\ ${ }^{1}$ Department of Gastroenterology, Endocrinology and Nutrition and ${ }^{2}$ Institute of Clinical Chemistry and Laboratory Medicine, University of Greifswald, \\ Greifswald, Germany, ${ }^{3}$ Pfizer Endocrine Care, Sollentuna, Sweden and ${ }^{4}$ Department of Pharmacy, Uppsala University, Uppsala, Sweden \\ (Correspondence should be addressed to J Moock; Email: joern.moock@uni-greifswald.de)
}

*(T Kohlmann and H Wallaschofski contributed equally)

\begin{abstract}
Objective: To analyse 12-month response to GH treatment in a single-country cohort of hypopituitary adult patients with GH deficiency (GHD) in regards to health-related quality of life (HRQoL) and insulin-like growth factor-1 (IGF-1) compared with values from general population sample. Moreover, association between the response in HRQoL and the IGF-1 values in patients and in the background population was investigated.

Design: HRQoL was assessed by quality of life assessment of GH deficiency in adults (QoL-AGHDA) in 651 patients retrieved from the German KIMS (Pfizer International Metabolic Database) before and after 12 months of GH replacement and in a sample drawn from a cross-sectional study in Germany $(n=2734)$. IGF-1 was measured in KIMS patients and in the population-based study with the same assay technique.

Results: In KIMS patients, mean QoL-AGHDA scores before GH replacement were $9.2 \pm 6.8(8.7 \pm 6.8)$ in women (men) and in the general population sample $4.5 \pm 5.3(4.3 \pm 5.0)$ in women (men). Mean differences in QoL-AGHDA scores were statistically significant for all age categories $(P<0.05)$. The mean IGF-1 SDS of KIMS patients before GH replacement was $-1.1 \pm 1.4(-0.8 \pm 1.4)$ in women (men). After GH replacement, a significant increase of IGF-1 concentration and a significant decrease of QoL-AGHDA scores near to age- and gender-specific population-based values were observed. Conclusions: This study confirms an improvement in HRQoL and an increase of IGF-1 SDS in GH-replaced adults, which approximated the values of general population. However, there was no association between IGF-1 values and HRQoL assessment as one of the important treatment outcomes.
\end{abstract}

European Journal of Endocrinology 160 17-24

\section{Introduction}

GH deficiency (GHD) in adults is a well-recognized distinct clinical condition (1). One of the most important impairments from a patient's point of view is the decline in health-related quality of life (HRQoL). The HRQoL decay is perceived in the areas of energy, emotional reaction, social behaviour, general health, self-control, anxiety, vitality, mood and sense of well-being measured by Nottingham Health Profile and the Psychological General Well-Being Schedule (2). Most studies showed a benefit of GH replacement on HRQoL (1). Although extensive data are now available documenting the impaired QoL associated with adult GHD, the mechanisms underlying this observation remain poorly understood. There are specific receptors expressed in the brain and after $\mathrm{GH}$ treatment, $\mathrm{GH}$ and insulin-like growth factor-1 (IGF-1) concentrations increase in cerebrospinal fluid (3). The highest concentration of GH and IGF-1 receptors has been found in the choroid plexus, followed by the pituitary, hippocampus, putamen, hypothalamus and thalamus $(4,5)$. These areas offer potential access into the $\mathrm{CN}$, and key limbic system structures known to be pivotal for the physiology of vegetative functions and in the control of behaviour, emotion and motivation, suggesting a possible central role for GH effects on QoL. However, the underlying mechanism and the effects of $\mathrm{GH}$ treatment on cognitive function as well as QoL are unclear. Moreover, there is little known about the association between changes in QoL and biochemical markers of GHD, especially IGF-1. However, these mechanisms appear to have a rapid onset 
of action, as most of the QOL improvement is observed to occur rapidly in affected GHD adults within the first 3 months of GH replacement $(6,7)$.

Apart from comparing the effect of GH replacement with placebo, another approach to assess HRQoL in GHD adults is to compare the effect of GH therapy with the values from the general population. Furthermore, population-based data are the background for the evaluation of HRQoL as a standard endpoint in clinical studies and for economic evaluation or health care decision making. Furthermore, there are only few studies on HRQoL in GHD patients in relation to their country-specific population-based data (8-11).

Therefore, the objectives of our present study were first to evaluate 12-month response to $\mathrm{GH}$ treatment in the German KIMS (Pfizer International Metabolic Database (12)) cohort of hypopituitary adult patients with GHD in regards to HRQoL and IGF-1 and in comparison with the values generated from a general population sample and secondly to investigate the association between quality of life assessment of growth hormone deficiency in adults (QoL-AGHDA) scores and IGF-1 concentrations in the German KIMS cohort as well as in the general population.

\section{Material and methods}

\section{Instrument}

HRQoL was measured by the QoL-AGDHA, a diseasespecific, one-dimensional, patient needs-based HRQoL instrument, developed specifically for the detection of deficits, needs achievement in areas that are affected in GHD adults (13-16). The measure consists of 25 questions with 'yes' or 'no' answers; a 'yes' answer indicates that the patient perceives a problem. The sum of 'yes' answers constitutes a score, with a high score denoting a poor HRQoL. The QoL-AGHDA showed satisfactory psychometric properties across a wide range of languages (15).

\section{Patient sample}

GH-deficient patients' information was retrieved from the German KIMS, a pharmaco-epidemiological survey of adult GH-deficient patients, and included sociodemographic characteristics, background clinical characteristics, QoL-AGHDA scores and IGF-1 values, at baseline and 12-month follow-up. In KIMS patients, until November 2002, serum IGF-1 was determined by RIA after acid-ethanol precipitation of IGF-binding proteins (Nichols Institute Diagnostics, San Juan Capistrano, CA, USA). Thereafter, a chemiluminescence immunoassay (Nichols Advantage System, Bad Vilbel, Germany) was introduced. Long-term reproducibility, measured during $>1$ year, showed a coefficient of variation $<9 \%$ of $130-850 \mu \mathrm{g} / \mathrm{l}$. The assay detection limit was $30 \mu \mathrm{g} / \mathrm{l}(12)$.

\section{General population sample (SHIP)}

About 3925 eligible participants of the 'Study of Health in Pomerania' (SHIP) consented to participate in this study. SHIP is a population-based study in the northeastern region of Germany, situated on the Baltic coast. The study was designed to provide comprehensive information of the state of health as well as the health-related behaviour and living conditions of the population in western Pomerania (17).

Information on HRQoL assessed by the QoL-AGHDA and socio-demographics were collected using a postal questionnaire. The questionnaire was administered in the first half of 2006 to the SHIP participants. IGF-1 concentrations were measured in all participants of the SHIP study. The blood samples were drawn from the cubital vein. Serum IGF-1 concentrations were determined by automated two-site chemiluminescence immunoassays (Nichols Advantage; Nichols Institute Diagnostica GmbH, Bad Vilbel, Germany) in the SHIP population (18). The analytical sensitivity of the assay was $6 \mathrm{ng} / \mathrm{ml}$. The IGF-1 assay has been calibrated against the World Health Organization International Reference Reagent 1988, IGF-I 87/518. Reference ranges of IGF-1 for the SHIP population have been computed and described elsewhere (19).

The medical ethics committee of the University of Greifswald approved the study protocol. All participants gave written informed consent.

\section{Statistical analysis}

Descriptive statistics included means, s.D.s, medians and proportions for demographic properties. Distributional comparisons between responders and non-responders were done by $\chi^{2}$-test. ANOVA and $t$-tests were used to examine subgroup differences. Dunnett's $t$-test, multiple comparison method, was performed to compare QoLAGDHA scores from age groups 20-59 years against the age group 60 years or older as post hoc assessment. Bivariate correlation analyses were performed using Pearson's correlation coefficient. A $P$ value less than 0.05 was considered statistically significant. Statistical analyses were performed using SPSS software version 15.0 (SPSS Inc., Chicago, IL, USA).

IGF-1 concentrations are described as SDS. SDS were calculated as (observed serum IGF-1 level - SHIP population mean serum IGF-1 level (standardized for age and gender)/SHIP population standardized S.D.).

\section{Results}

\section{Characteristics of KIMS patients}

The analysis was performed using data of 651 consecutively documented adult patients $(n=288$ women, $n=363$ men) with GHD enrolled in the German KIMS database. These patients had either never received 
GH replacement or had not received GH for at least 6 months before entry into KIMS. All patients included in the study had GHD proven by insulin-induced hypoglycaemia, arginine or glucagon as primary stimulus. Childhood onset-GHD was reported in 173 of 651 patients. At entry to KIMS (baseline visit), the mean age was $44.8 \pm 13.3$ years $(45.7 \pm 12.8$ for women and $44.2 \pm 13.8$ for men). Details of the aetiology, clinical characteristics and other hormone treatments of the KIMS patients are detailed in Tables 1 and 2. The most common causes of GHD in the KIMS cohort were nonfunctioning pituitary adenoma $n=227$ (34.9\%), craniopharyngioma $n=106(16.3 \%)$, idiopathic/empty sella $n=76(11.7 \%)$ and prolactinoma $n=64(9.8 \%)$. All patients received a low starting dose of $\mathrm{GH}(0.1-$ $0.3 \mathrm{mg} /$ day), which was administered as a daily s.c. injection and was adjusted individually for each patient according to the clinical response and serum IGF-1 concentrations. The mean daily doses were $0.31 \pm 0.13 \mathrm{mg} /$ day after 6 months of treatment, and $0.29 \pm 0.15 \mathrm{mg} /$ day after 12 months. In addition, most of the patients received pituitary hormone replacement therapy (Table 2). QoL-AGHDA scores and IGF-1 concentrations were obtained at baseline and after 12 months of GH replacement therapy.

\section{Characteristics of the general population sample (SHIP)}

In total, 3925 participants of SHIP received a postal questionnaire. Of these, $78(2.0 \%)$ were returned because target subjects had moved, or were deceased. Of the remaining 3847 subjects, 25 (0.7\%) refused participation, by calling the study centre. Around 2814 subjects returned completed questionnaires. Of these, $48(1.7 \%)$ were excluded from further analysis, because of incomplete data. In total, 2768 questionnaires ( $n=1486$ women, $n=1282$ men) were available for analysis. The overall response was $71.6 \%$. The mean age of SHIP participants was $49.3 \pm 15.3(48.1 \pm 15.2$ for women and 50.8 \pm 15.2 for men).

Age, gender and IGF-1 concentrations were known variables for non-responders. IGF-1 means did not differ between responders and non-responders with respect to age and gender (data not presented).

\section{QoL-AGHDA scores of KIMS patients and SHIP participants}

Age- and gender-specific mean QoL-AGHDA scores of KIMS patients and SHIP individuals are presented in Table 3. The overall mean QoL-AGHDA score of KIMS patients was $8.9 \pm 6.8$ and $4.5 \pm 5.1$ of SHIP respondents. ANOVA indicated that variability in QoL-AGHDA scores was not statistically significantly explained by gender $(P=0.075)$, whereas age was a significant predictor $(P<0.001)$. Dunnett's post hoc analysis revealed that, QoL-AGDHA scores from the younger groups (20-59 years) were significantly lower, indicating better HRQoL compared with respondents aged 60 years or older (all $P$ values $P<0.001$ ).

\section{QoL-AGHDA scores: comparisons between KIMS patients and SHIP participants}

Compared with SHIP participants, KIMS patients at baseline had reduced HRQoL according to QoL-AGHDA

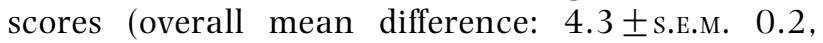
$P<0.001)$. Mean QoL-AGHDA scores at baseline were significantly higher in the KIMS cohort compared with SHIP participants when analysed by gender (women: $9.2 \pm 6.8$ (KIMS) vs $4.5 \pm 5.3$ (SHIP), $P<0.001$; men: $8.7 \pm 6.8$ (KIMS) vs $4.3 \pm 5.0$ (SHIP), $P<0.001$ ). In both KIMS patient groups (men and women), baseline QoL-AGHDA scores increased with age until the age of 50-59 years, dropping subsequently in patients aged 60 years or older (Table 3 and Fig. 1a and c). Moreover, mean QoL-AGHDA scores by gender and age for KIMS

Table 1 Aetiology of GH deficiency (GHD) patients in KIMS Germany.

\begin{tabular}{|c|c|c|c|c|c|c|c|c|c|c|c|c|}
\hline & \multicolumn{12}{|c|}{ Age groups } \\
\hline & \multicolumn{2}{|c|}{ Total } & \multicolumn{2}{|c|}{20} & \multicolumn{2}{|c|}{30} & \multicolumn{2}{|c|}{40} & \multicolumn{2}{|c|}{50} & \multicolumn{2}{|c|}{$60+$} \\
\hline & $n$ & $\%$ & $n$ & $\%$ & $n$ & $\%$ & $n$ & $\%$ & $n$ & $\%$ & $n$ & $\%$ \\
\hline Number of patients & 651 & 100 & 108 & 16.6 & 144 & 22.1 & 146 & 22.4 & 159 & 24.4 & 94 & 14.5 \\
\hline Idiopathic/empty sella & 76 & 11.7 & 29 & 38.2 & 19 & 25.0 & 13 & 17.1 & 11 & 14.5 & 4 & 5.3 \\
\hline Craniopharyngioma & 106 & 16.3 & 29 & 27.4 & 28 & 26.4 & 19 & 17.9 & 22 & 20.8 & 8 & 7.5 \\
\hline \multicolumn{13}{|l|}{ Pituitary adenoma } \\
\hline Non-functioning & 227 & 34.9 & 4 & 1.8 & 28 & 12.3 & 51 & 22.5 & 81 & 35.7 & 63 & 27.8 \\
\hline Prolactinoma & 64 & 9.8 & 7 & 10.9 & 22 & 34.4 & 15 & 23.4 & 15 & 23.4 & 5 & 7.8 \\
\hline ACTH & 33 & 5.1 & 7 & 21.2 & 6 & 18.2 & 9 & 27.3 & 4 & 12.1 & 7 & 21.2 \\
\hline $\mathrm{GH}$ & 11 & 1.7 & 0 & 0.0 & 3 & 27.3 & 4 & 36.4 & 3 & 27.3 & 1 & 9.1 \\
\hline Trauma & 27 & 4.2 & 4 & 14.8 & 17 & 63.0 & 5 & 18.5 & 1 & 3.7 & 0 & 0.0 \\
\hline $\begin{array}{l}\text { Sheehan/post partum } \\
\text { necrosis }\end{array}$ & 20 & 3.1 & 1 & 5.0 & 5 & 25.0 & 7 & 35.0 & 5 & 25.0 & 2 & 10.0 \\
\hline CNS tumours & 19 & 2.9 & 8 & 42.1 & 6 & 31.6 & 3 & 15.8 & 2 & 10.5 & 0 & 0.0 \\
\hline Others & 68 & 10.4 & 16 & 23.5 & 11 & 16.2 & 17 & 25.0 & 13 & 19.1 & 11 & 16.2 \\
\hline
\end{tabular}


Table 2 Baseline clinical characteristics of pituitary insufficiency, replacement regime and additional therapy of KIMS patients.

\begin{tabular}{|c|c|c|c|c|c|c|c|c|c|c|c|c|}
\hline & \multicolumn{12}{|c|}{ Age groups } \\
\hline & \multicolumn{2}{|c|}{ Total } & \multicolumn{2}{|c|}{20} & \multicolumn{2}{|c|}{30} & \multicolumn{2}{|c|}{40} & \multicolumn{2}{|c|}{50} & \multicolumn{2}{|c|}{$60+$} \\
\hline & $n$ & $\%$ & $n$ & $\%$ & $n$ & $\%$ & $n$ & $\%$ & $n$ & $\%$ & $n$ & $\%$ \\
\hline \multicolumn{13}{|c|}{ Pituitary replacement therapy } \\
\hline Adrenal insufficiency & 496 & 100 & 80 & 16.1 & 100 & 20.2 & 116 & 23.4 & 135 & 27.2 & 65 & 13.1 \\
\hline $\begin{array}{l}\text { Hypothyroidism } \\
\text { Hypogonadism }\end{array}$ & 521 & 100 & 85 & 16.3 & 114 & 21.9 & 119 & 22.8 & 134 & 25.7 & 69 & 13.2 \\
\hline Male & 420 & 100 & 65 & 15.5 & 62 & 14.8 & 114 & 27.1 & 137 & 32.6 & 42 & 10.0 \\
\hline Female & 266 & 100 & 25 & 9.4 & 60 & 22.6 & 113 & 42.5 & 44 & 16.5 & 24 & 9.0 \\
\hline Diabetes insipidus & 189 & 100 & 38 & 20.1 & 46 & 24.3 & 43 & 22.8 & 45 & 23.8 & 17 & 9.0 \\
\hline
\end{tabular}

patients' were significantly higher, indicating lower HRQoL, compared with the SHIP individuals $(P<0.001$ in most age categories, Table 3).

Mean QoL-AGHDA scores in KIMS patients at baseline and 12-month-follow-up are shown by age groups in Fig. 1a (women) and 1c (men) and in comparison with mean QoL-AGHDA scores of SHIP participants. The HRQoL of patients with GHD improved after GH replacement therapy. This was revealed by a decrease in mean QoL-AGHDA of $3.1 \pm 5.5$ points $(P<0.001)$ in women and $2.1 \pm 5.1$ points $(P<0.001)$ in men at 12-month follow-up respectively. Despite the decrease in the mean QoL-AGHDA scores in KIMS patients after 12 months of $\mathrm{GH}$ treatment, the QoL-AGHDA scores in patients remained higher compared with those in the SHIP cohort. Overall, mean difference of QoL-AGHDA scores between KIMS patients' and the SHIP subjects after 12 months of $\mathrm{GH}$ therapy was 1.6 points ( \pm s.e.M. $0.34, P<0.001)$.

\section{IGF-1 concentrations: comparisons between KIMS patients and SHIP participants and relation with QoL-AGHDA}

Mean baseline and 12 month IGF-1 concentrations in KIMS patients and SHIP participants (relative to values in the SHIP subjects) are presented in Fig. 1b (women) and $1 \mathrm{~d}$ (men). Mean IGF-1 levels at baseline were $84.4 \pm 55.9$ and $107.1 \pm 62.5 \mathrm{ng} / \mathrm{ml}$ in female and male patients respectively. After 12 months of $\mathrm{GH}$ replacement therapy, serum IGF-1 concentrations had increased by $175.4 \pm 82.9$ and $224.6 \pm 105.4 \mathrm{ng} / \mathrm{ml}$ in women and men. This corresponded to 12-month increases in IGF-1 SDS from -0.8 to 1.6 , in men and from -1.2 to 0.7 in women. With respect to age, mean IGF-1 levels of the KIMS cohort were between the -2 and -1 s.D. of the general population in SHIP at baseline and have increased after 12-months GH replacement therapy to the upper reference range for all age groups. Increasing IGF-1 levels and decreasing QoL-AGHDA scores were observed in both gender and all age groups.

From a visual impression, KIMS patients with IGF-1 SDS below -2 and above +2 SDS, showed higher QoLAGHDA scores than patients who had IGF-1 SDS between -2 and +2 SDS (Fig. $2 \mathrm{a}$ and b). However, there was no statistically significant association between IGF-1 values and QoL-AGHDA scores in both the general population sample $(r=-0.048, P=0.093)$ and the KIMS cohort (baseline: $r=0.019, P=0.709$; 12-month follow-up: $r=-0.021, P=0.770)$. Furthermore, correlation of mean differences of IGF-1 values

Table 3 Quality of life assessment of GH deficiency in adults (QoL-AGHDA) scores in GH-deficient patients in KIMS before GH replacement (baseline) and the Study of Health in Pomerania (SHIP) individuals.

\begin{tabular}{|c|c|c|c|c|c|c|c|c|c|c|}
\hline \multirow[b]{2}{*}{ Sex } & \multirow[b]{2}{*}{ Age group } & \multicolumn{3}{|c|}{ KIMS patients (baseline) } & \multicolumn{5}{|c|}{ General population } & \multirow[b]{2}{*}{$P$ value } \\
\hline & & Mean & S.D. & Median & $N$ & Mean & S.D. & Median & $N$ & \\
\hline \multirow[t]{6}{*}{ Women } & 20 & 6.6 & 5.8 & 4.5 & 33 & 4.1 & 4.8 & 2.0 & 208 & $<0.05$ \\
\hline & 30 & 8.5 & 7.0 & 8.0 & 68 & 3.7 & 4.7 & 2.0 & 287 & $<0.001$ \\
\hline & 40 & 9.9 & 6.9 & 9.0 & 77 & 4.3 & 5.2 & 3.0 & 283 & $<0.001$ \\
\hline & 50 & 10.6 & 6.0 & 9.5 & 63 & 3.9 & 4.8 & 2.0 & 314 & $<0.001$ \\
\hline & $60+$ & 8.9 & 7.3 & 7.5 & 47 & 6.1 & 5.9 & 4.0 & 383 & $<0.05$ \\
\hline & Total & 9.2 & 6.8 & 9.0 & 288 & 4.5 & 5.3 & 3.0 & 1475 & $<0.001$ \\
\hline \multirow[t]{6}{*}{ Men } & 20 & 8.2 & 6.8 & 7.0 & 75 & 4.0 & 4.8 & 2.5 & 126 & $<0.001$ \\
\hline & 30 & 8.0 & 6.6 & 7.0 & 76 & 3.6 & 4.3 & 2.0 & 215 & $<0.001$ \\
\hline & 40 & 9.8 & 7.7 & 9.0 & 69 & 3.9 & 4.8 & 2.0 & 242 & $<0.001$ \\
\hline & 50 & 9.1 & 6.5 & 8.0 & 96 & 3.7 & 4.7 & 2.0 & 268 & $<0.001$ \\
\hline & $60+$ & 8.5 & 6.6 & 6.0 & 47 & 5.5 & 5.5 & 4.0 & 408 & $<0.05$ \\
\hline & Total & 8.7 & 6.8 & 7.5 & 363 & 4.3 & 5.0 & 3.0 & 1259 & $<0.001$ \\
\hline Total & & 8.9 & 6.8 & 8.0 & 651 & 4.5 & 5.1 & 3.0 & 2734 & $<0.001$ \\
\hline
\end{tabular}



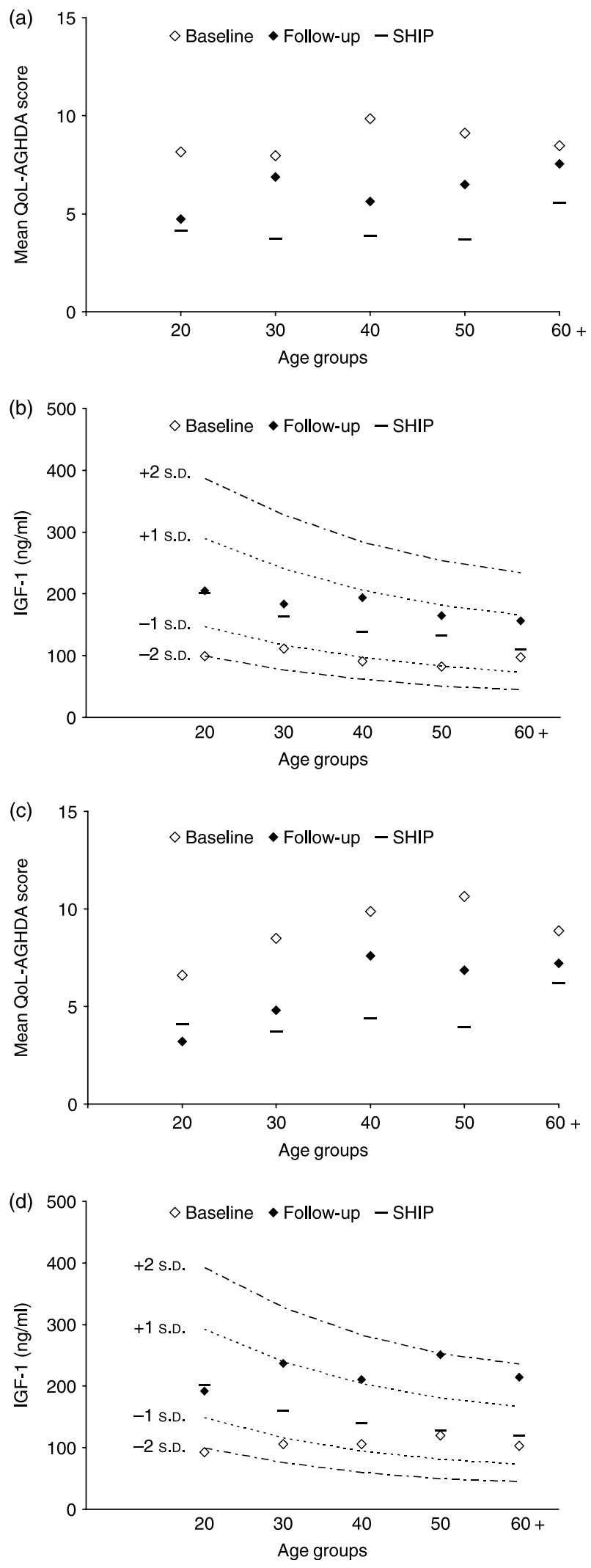

(baseline - 12 months follow-up) and QoL-AGHDA scores (baseline - 12 months follow-up) failed statistic significance.

\section{Discussion}

This study reports the results of QoL-AGHDA scores and IGF-1 levels in a cohort of patients with GHD of the German KIMS cohort at baseline and after 12 months of GH replacement, and compares them with the results obtained in a general population sample from the German SHIP study. Mean QoL-AGHDA scores of the German KIMS cohort are consistent with those from the previously published studies in Sweden and the Netherlands respectively, which indicate a substantial HRQoL deficit in untreated hypopituitary patients with GHD independent of gender and age (10). However, there were no differences in mean QoL-AGHDA scores between males and females in either the KIMS cohort or as in the general population sample, which runs counter to previous studies (20-22).

Our results demonstrated a significant improvement in HRQoL and an increase of IGF-1 concentration in GHD patients, approaching QoL-AGHDA scores and IGF-1 levels of the SHIP population after 12 months of GH replacement therapy. We demonstrated that the positive effect of $\mathrm{GH}$ replacement on HRQoL was independent of gender or age, even in patients $>60$ years. On the other hand, our data indicate differences in age groups with a smaller decrease of QoL-AGHDA scores especially in patients $>40$ years compared with patients in the 20 years group. This might depend on differences in $\mathrm{GH}$ replacement regimens in study subjects. All patients received a low starting dose of GH $(0.1-0.3 \mathrm{mg} /$ day), which was administered as a daily s.c. injection and was adjusted individually for each patient according to the clinical response and serum IGF-1 concentrations in the different study centres. The mean daily doses were $0.31 \pm$ $0.13 \mathrm{mg} /$ day after 6 months of treatment, and $0.29 \pm$ $0.15 \mathrm{mg} /$ day after 12 months.

Koltowska-Häggstrom and colleagues demonstrated that long-term GH replacement maintained the initial positive improvement of HRQoL after 3.5-7 years (10). As reported in this study, the most improvement of HRQoL occurred within the first 12 months of GH replacement therapy. Mean differences in QoL-AGHDA scores between the general population and GHD patients at 12-month follow-up ranged between 1.5 (Sweden) and 3.3 (Spain) points (10). Based on our

Figure $1(a-d)$ Decrease of Qol-AGHDA score and increase of IGF-1 concentration in GHD patients compared with the general population (SHIP). (a) Mean Qol-AGHDA scores at baseline and 12-month follow-up (women). (b) Mean IGF-1 values at baseline and 12-month follow-up (women). (c) Mean Qol-AGHDA scores at baseline and 12-month follow-up (men). (d) Mean IGF-1 values at baseline and 12-month follow-up (men). 

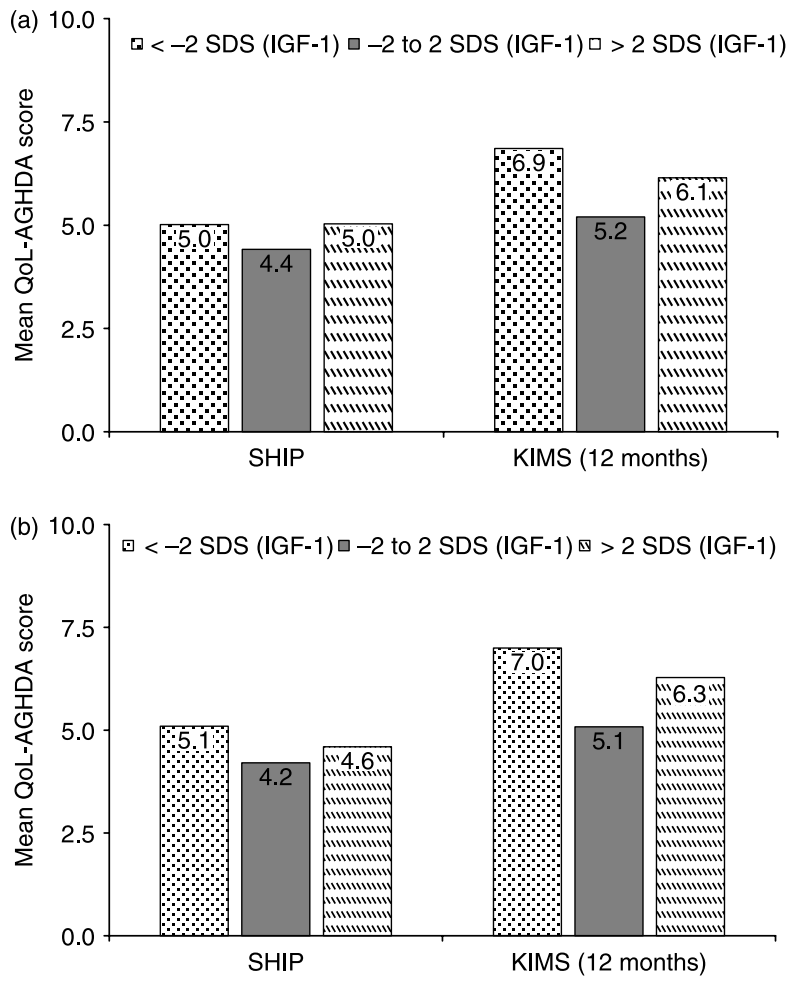

Figure 2 (a) Mean QoL-AGHDA scores of SHIP participants and KIMS patients by percentiles of IGF-1 value range (women). (b) Mean QoL-AGHDA scores of SHIP participants and KIMS patients by percentiles of IGF-1 value range (men).

results, the German KIMS patients are located at immediate vicinity to Sweden, with an overall mean difference of 1.6 points after 12 months of $\mathrm{GH}$ replacement between KIMS patients and the SHIP respondents.

However, there are few limitations to our study, which should be considered in the interpretation of the present results. First, the sample was drawn in one region of Germany only. It is unclear whether this population is representative for the whole country due to its low population density and different socioeconomic structure. On that condition, QoL-AGHDA scores of the SHIP sample should not be treated as population-based norm scores.

Secondly, our results suggest that GH replacement in adults with GHD is related to an increase in IGF-1 concentrations and an improvement in overall HRQoL. During the first 12 months of treatment, the IGF-1 levels increased and the QoL-AGHDA scores decreased to approximate population reference levels. But the results failed to show an association between QoLAGHDA scores and IGF-1 levels in the general population sample as well as in our KIMS cohort at baseline and at 12-month follow-up respectively. Thus, our study results indicate that total serum IGF-1, measured by commercially available assays do not correlate with HRQoL assessment in patients with GHD as well as in the general population. This important finding is in line with the previous studies, which failed to demonstrate a statistical significant relationship between HRQoL assessed by QoL-AGHDA and IGF-1 concentrations in patients with GHD (22-24), with the exception of Svensson et al. and Giusti et al. $(25,26)$. Svensson and colleagues reported a weak correlation $(r<0.20)$ between baseline QoL-AGHDA scores and IGF-1 SDS, suggesting that patients with the most impaired HRQoL had the highest IGF-1 SDS. Giusti et al. reported a weak correlation between IGF-1 values and QoL assessment by Hamilton Depression scale $(n=13$; $r=-0.56 ; P=0.05)$ (26). Both latter studies are limited by low numbers of investigated patients and these results cannot be reproduced in our large cohort of patients and control subjects. Moreover, studies investigating HRQoL and IGF-1 in patients with acromegaly confirmed our lack of association between IGF-1 levels and HRQoL assessment $(27,28)$. We conclude that the improvement of HRQoL in GHD patients seems to be a complex mechanism that cannot be simply reflected by IGF-1 values or favourable changes in body composition for example (29). We do not know the specific reasons of these findings. Non-specific effects of treatment, natural history, response shift or even physiological actions of GH may have influenced this finding and patients' subjective perception addressing HRQoL is likely to be multifactorial in origin.

In conclusion, the results described in this report reconfirm the presence of impaired HRQoL in patients with GHD, relative to general population values. In addition, our findings suggest that $\mathrm{GH}$ replacement therapy increases IGF-1 concentrations and improves HRQoL to near general population values, but that there is no clear association between the two.

\section{Declaration of interest}

J Moock, C Albrecht, N Friedrich, H Völzke, M Nauck, T Kohlmann, $\mathrm{H}$ Wallaschofski have nothing to declare. M Koltowska-Haggström is a current employee of Pfizer.

\section{Funding}

SHIP is part of the Community Medicine Net (http://www.medizin. uni-greifswald.de/cm) of the University of Greifswald, which is funded by grants from the German Federal Ministry of Education and Research (BMBF, grant 01ZZ96030); the Ministry for Education, Research, and Cultural Affairs; and the Ministry for Social Affairs of the Federal State of Mecklenburg-West Pomerania. Pfizer provided partial grant support for the determination of plasma samples and data analysis.

\section{Acknowledgements}

H Wallaschofski appears on behalf of the German KIMS board. The contributions to data collection made by field workers, study physicians, ultrasound technicians, interviewers and computer assistants are gratefully acknowledged. Moreover, the authors would like to express thanks to the participants of KIMS in Germany, who provided the data on their patients and to the colleagues working at 
KIMS Medical Outcomes in Karlsruhe and Stockholm (Dr I Harsch, University of Erlangen; Prof. Dr M Buchfelder, University of Erlangen; Prof. Dr M Weber, University of Mainz; Prof. Dr C Kasperk, Prof. Dr P Nawroth, University of Heidelberg; Dr C Auernhammer, University of Munich; Prof. Dr K Mann, University of Essen; Dr J Krug, Clinical Center St Georg Leipzig; Prof. Dr R F Hampel, University of Rostock; Prof. Dr U Tuschy, University of Erfurt; Prof. Dr N Stahnke, Endokrinologikum Hamburg; Prof. Dr H-U Häring, University of Tübingen; Dr H Mönig, University of Kiel; Prof. Dr D Klingmüller, University of Bonn; Prof. Dr P Ball, Lübeck; Dr J Ittner, Augsburg; Dr C Kerber, HELIOS Schwerin; Dr R Gellner, University of Münster; Prof. Dr K-J Gräf, Endokrinologikum Berlin; Prof. Dr G Stalla, Max-PlanckInstitute Munich; Prof. Dr F-U Beil, UKE Hamburg; Dr J Santen, Dr R Engelbach, Frankfurt; Dr M Faust, University of Cologne; Dr K Reschke, University of Magdeburg; Prof. Dr P Weisweiler, Munich; Dr M Droste, Oldenburg; Dr U Deuß, Cologne; Dr C Terkamp, M H H Hanover; PD Dr H Wallaschofski, University of Greifswald; Dr K Ventzke, Bremen; Prof. Dr H M Schulte, Endokrinologikum Hamburg; Dr J Schopohl, University of Munich; Dr C Jaursch-Hanke, DKD GFF Wiesbaden; Dr M Gruber, University of Dresden; Prof. Dr M Stumvoll, University of Leipzig; Prof. Dr O A Müller, 'RotKreuz' Hospital Munich; Prof. Dr H Stracke, University of Giessen; Dr W Faßbender, Hospital zum Hl. Geist Kempen; Dr E Jochum, Krankenhaus der Barmherzigen Brüder, Trier; Dr F Demtröder, Städtisches Klinikum Dortmund gGmbH; Prof. Dr T H Schürmeyer, Mutterhaus der Borromäerinnen Trier; Dr F Schröder, Brandenburg; Prof. Dr K Badenhoop, University of Frankfurt; Prof. Dr W Karges, University of Aachen; Prof. Dr J Seufert, University of Freiburg; Prof. Dr J Hensen, Klinikum Nordstadt Hanover; Prof. Dr U Bogner, Berlin; Dr R Gutekunst, Lübeck; Prof. Dr P Kann, University of Marburg; Dr U Schröder, Endokrinologikum Hanover; Dr U Plöckinger, University of Berlin; Dr K Wiener, Cottbus: Dr J Feldkamp, Bielefeld; Dr A Hoffmann, Cologne; Dr J Wildbrett, Dresden; Dr H Dirks, Bremen; Prof. Dr U Schneyer, University of Halle; Dr M Wolf, Hospital Bietigheim-Bissingen; Dr V Hector, Hamburg; Dr A Figge, University of Bochum; Prof. Dr A Hübner, University of Dresden; Dr H J Kröhne, Jena; Dr C Weber, Halberstadt; Dr W Omran, Mainz; Dr B Gerbert, Endokrinologikum Dresden). The KIMS database is sponsored by Pfizer.

\section{References}

1 Carroll PV, Christ ER, Bengtsson BA, Carlsson L, Christiansen JS, Clemmons D, Hintz R, Ho K, Laron Z, Sizonenko P, Sonksen PH, Tanaka T \& Thorne M. Growth hormone deficiency in adulthood and the effects of growth hormone replacement: a review. Growth Hormone Research Society Scientific Committee. Journal of Clinical Endocrinology and Metabolism 199883 382-395.

2 Carroll PV, Littlewood R, Weissberger AJ, Bogalho P, McGauley G, Sönksen PH \& Russell-Jones DL. The effects of two doses of replacement growth hormone on the biochemical, body composition and psychological profiles of growth hormone-deficient adults. European Journal of Endocrinology 1997137 146-153.

3 van Dam PS. Somatotropin therapy and cognitive function in adults with GHD review. Treatments in Endocrinology 20065 159-170.

4 Nyberg F \& Burman P. Growth hormone and its receptors in the central nervous system - location and functional significance. Hormone Research 199645 18-22.

5 Lai ZN, Emtner M, Roos P \& Nyberg F. Characterization of putative growth hormone receptors in human choroid plexus. Brain Research $1991546222-226$.

6 Drake WM, Coyte D, Camacho-Hübner C, Jivanji NM, Kaltsas G, Wood DF, Trainer PJ, Grossman AB, Besser GM \& Monson JP. Optimizing growth hormone replacement therapy by dose titration in hypopituitary adults. Journal of Clinical Endocrinology and Metabolism 199883 3913-3919.

7 Murray RD, Skillicorn CJ, Howell SJ, Lissett CA, Rahim A, Smethurst LE \& Shalet SM. Influences on quality of life in GH deficient adults and their effect on response to treatment. Clinical Endocrinology 199951 565-573.
8 Koltowska-Häggström M, Hennessy S, Mattsson AF, Monson JP \& Kind P. Quality of life assessment of growth hormone deficiency in adults (QoL-AGHDA): comparison of normative reference data for the general population of England and Wales with results for adult hypopituitary patients with growth hormone deficiency. Hormone Research 200564 46-54.

9 Badia X, Lucas A, Sanmarti A, Roset M \& Ulied A. One-year followup of quality of life in adults with untreated growth hormone deficiency. Clinical Endocrinology 199849 765-771.

10 Koltowska-Häggström M, Mattsson AF, Monson JP, Kind P, Badia X, Casanueva FF, Busschbach J, Koppeschaar HP \& Johannsson G. Does long-term GH replacement therapy in hypopituitary adults with GH deficiency normalise quality of life? European Journal of Endocrinology 2006155 109-119.

11 Wirén L, Whalley D, McKenna S \& Wilhelmsen L. Application of a disease-specific, quality-of-life measure (QoL-AGHDA) in growth hormone-deficient adults and a random population sample in Sweden: validation of the measure by rasch analysis. Clinical Endocrinology 200052 143-152.

12 Gutiérrez LP, Koltowska-Häggström M, Jönnson PJ, Mattson AF, Svensson D, Westberg B \& Luger A. Registries as a tool in evidencebased medicine: example of KIMS (Pfizer International Metabolic Database). Pharmacoepidemiology and Drug Safety 2008 17 90-102.

13 Holmes SJ \& Shalet SM. Factors influencing the desire for longterm growth hormone replacement in adults. Clinical Endocrinology 199543 151-157.

14 McKenna SP \& Doward LC. Quality-of-life assessment of adults with growth hormone deficiency. Implications for drug therapy. PharmacoEconomics 19946 434-441.

15 McKenna S \& Doward L. Measuring quality of life in adults with growth hormone deficiency. Clinical Endocrinology 199645 507-508.

16 McKenna SP, Doward LC, Alonso J, Kohlmann T, Niero M, Prieto L \& Wiren L. The QoL-AGHDA: an instrument for the assessment of quality of life in adults with growth hormone deficiency. Quality of Life Research 19998 373-383.

17 John U, Greiner B, Hensel E, Lüdemann J, Piek M, Sauer S, Adam C, Born G, Alte D, Greiser E, Haertel U, Hense HW, Haerting J, Willich S \& Kessler C. Study of Health in Pommerania (SHIP): a health examination survey in an East German region: objectives and design. Sozial- und Präventivmedizin 200046 146-194.

18 Völzke H, Friedrich N, Schipf S, Haring R, Luedemann J, Nauck M, Dorr M, Brabant G \& Wallaschofski H. Association between serum insulin-like growth factor-I levels and thyroid disorders in a population-based study. Journal of Clinical Endocrinology and Metabolism 200792 4039-4045.

19 Friedrich N, Alte D, Volzke H, Spilcke-Liss E, Lerch MM, Kohlmann T, Nauck M \& Wallaschofski H. Reference ranges of serum IGF-I and IGFBP-3 levels in a general adult population: results of the Study of Health in Pomerania (SHIP). Growth Hormone and IGF Research 200818 228-233.

20 Bengtsson BA, Abs R, Bennmarker H, Monson JP, FeldtRasmussen U, Hernberg-Stahl E, Westberg B, Wilton P \& Wuster $\mathrm{C}$. The effects of treatment and the individual responsiveness to growth hormone $(\mathrm{GH})$ replacement therapy in 665 GH-deficient adults. KIMS Study Group and the KIMS International Board. Journal of Clinical Endocrinology and Metabolism 199984 3929-3935.

21 Svensson J, Mattsson A, Rosén T, Wirén L, Johannsson G, Bengtsson BA \& Koltowska-Häggström M. Swedish KIMS National Board. Three-years of growth hormone (GH) replacement therapy in GH-deficient adults: effects on quality of life, patient-reported outcomes and healthcare consumption. Growth Hormone and IGF Research 200414 207-215.

22 Hernberg-Ståhl E, Luger A, Abs R, Bengtsson B- $\AA$, FeldtRasmussen U, Wilton P, Westberg B \& Monson JP. Healthcare consumption decreases in parallel with improvements in quality of life during GH replacement in hypopituitary adults with $\mathrm{GH}$ deficiency. Journal of Clinical Endocrinology and Metabolism 2001 86 5277-5281. 
23 Barkan AL. The 'quality of life-assessment of growth hormone deficiency in adults' questionnaire: can it be used to assess quality of life in hypopituitarism? Journal of Clinical Endocrinology and Metabolism 2001 86 1905-1907.

24 Woodhouse LJ, Mukherjee A, Shalet SM \& Ezzat S. The influence of growth hormone status on physical impairments, functional limitations, and health-related quality of life in adults. Endocrine Reviews 200627 287-317.

25 Svensson J, Finer N, Bouloux P, Bevan J, Jonsson B, Mattsson AF, Lundberg M, Harris PE, Koltowska-Häggström M, Monson JP \& KIMS International Board. Growth hormone $(\mathrm{GH})$ replacement therapy in $\mathrm{GH}$ deficient adults: predictors of one-year metabolic and clinical response. Growth Hormone and IGF Research 200717 67-76.

26 Giusti M, Meineri D, Malagamba D, Cuttica CM, Fattacciu G, Menichini U, Rasore E \& Giordano G. Impact of recombinant human growth hormone treatment on psychological profiles in hypopituitary patients with adult-onset growth hormone deficiency. European Journal of Clinical Investigation 199828 13-19.
27 Neggers SJ, van Aken MO, de Herder WW, Feelders RA, Janssen JA, Badia X, Webb SM \& van der Lely AJ. Quality of life in acromegalic patients during long-term somatostatin analog treatment with and without pegvisomant. Journal of Clinical Endocrinology and Metabolism 200898 3853-3859.

28 Rowles SV, Prieto L, Badia X, Shalet SM, Webb SM \& Trainer PJ. Quality of life (QOL) in patients with acromegaly is severely impaired: use of a novel measure of QOL: acromegaly quality of life questionnaire. Journal of Clinical Endocrinology and Metabolism $2005903337-3341$.

29 Mukherjee A, Adams JE, Smethurst L \& Shalet SM. Interdependence of lean body mass and total body water, but not quality of life measures, during low dose GH replacement in GH-deficient adults. European Journal of Endocrinology 2005153 661-668.

Received 22 October 2008

Accepted 28 October 2008 